\title{
the medico-psychological unit of the military field hospital in the Jordanian camp of refugees, experience of Moroccan military health service
}

\author{
A.CHAOUQ(1)I, M.GARTOUM(2), S.GASSIM(1), H.ZAKARIA(1), K.MOUHADI(2). \\ (1) HOPITAL MILITAIRE MY ISMAIL MEKNES- MAROC/( \\ (2) 2) HOPITAL MILITAIRE D'INSTRUCTION MOHAMED V- RABAT- MAROC
}

\begin{abstract}
A Moroccan medical-surgical hospital has been deployed to assist Syrian refugees in Azaatari camp in Jordan, it was opened near the Syrian-Jordanian border in the outskirts of the city of Almafraq in August 2012. Initially there were 4000 refugees, this number increased in December 2013 to 120000 refugees. Psychiatric care is provided by the medico-psychological unit 24 hours a day by a military psychiatrist accompanied by a specialized nurse. They also provide liaison psychiatry for hospitalized patients at the Moroccan hospital for various somatic pathologies. The psychological difficulties related to life in the refugee camp and the new status of the people displaced persons reveal or increase latent psychiatric disorders. The psychiatric activity helped to alleviate the suffering of psychic traumatized refugees chronic psychiatric patients and children who are often neglected in armed conflicts. In addition to psychiatric care, he had brought solidarity and compassion for a poor and fragile population, which has no deadline for its ordeal and especially who has a permanent fear of losing his life or that of his relatives remained in Syria. Azaatari camp was opened near the Syrian-Jordanian border nearby from the city of Almafraq in August 2012 with initially 4000 refugees. This number is in December 2013 to 120,000 refugees. The camp became the $5^{\text {th }}$ city of Jordan in number of inhabitants. It's a challenge in terms of taking overall burden of primary needs (shelter, water, food, security, etc.) and preventive and curative medical care.
\end{abstract}

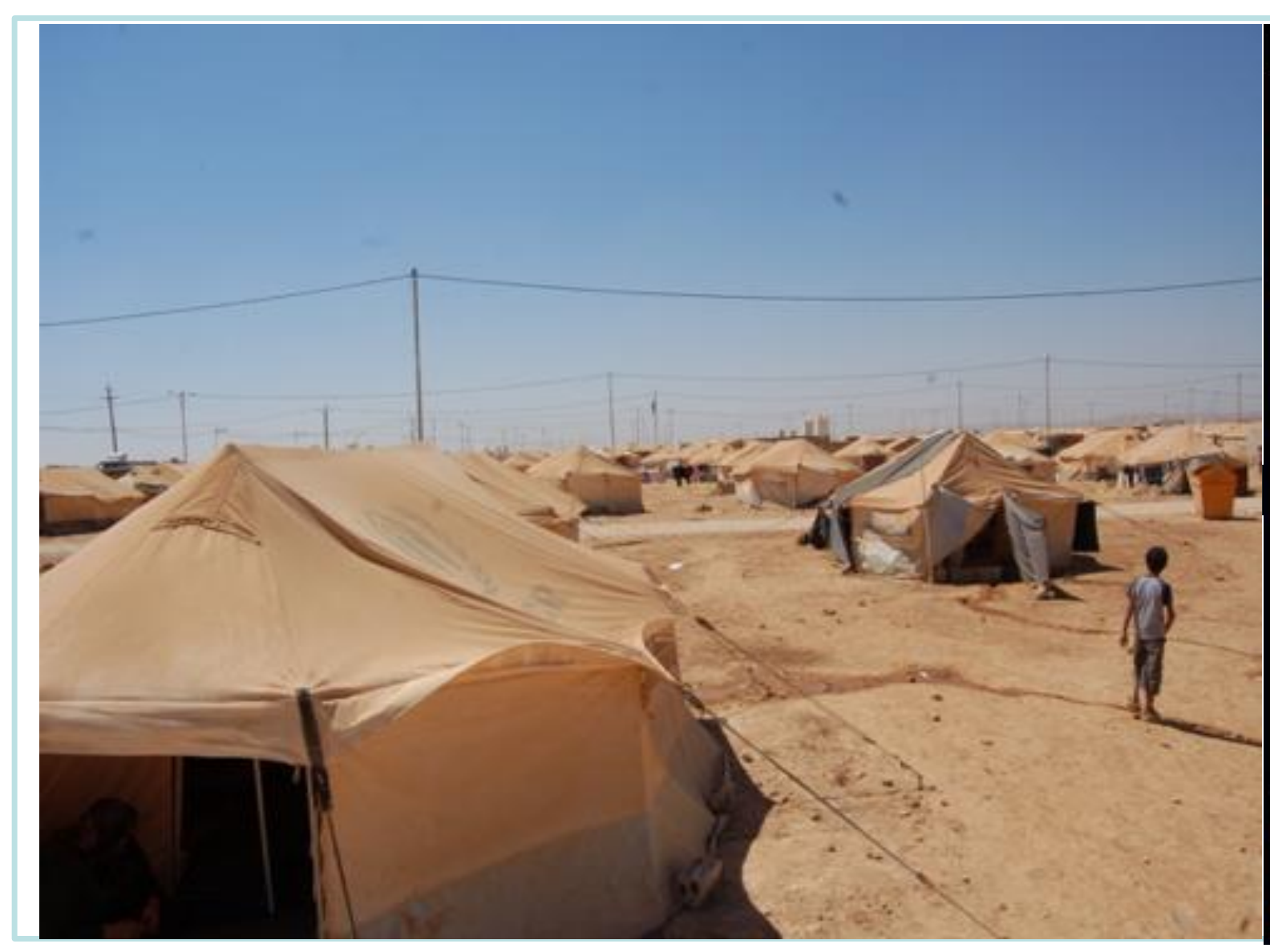

The psycho traumatic pathology $(2,3)$ among these refugees is prevalent with forms observed in young children. We also observed many addictive behaviors to benzodiazepines in personalities pathological. And there was another category of chronically ill patients who were already followed by psychiatrists in Syria, remained without care and without and who consulted for psychotropic drugs. Then there were the psychiatric emergencies especially the major depressive states with a suicidal risk among young girls and single women in the camp, who were victims of harassment or rape.

The reason for consultation in children was mostly a traumatic repetition syndrome with nightmares, repetitive drawings or for enuresies without infections urinary tract, eating disorders, or a change in character with tantrums, a brutal withdrawal with prostration and aboulia.

The care is most often outpatient with appointments not exceeding five days associated with a psychotropic endowment of short-term in case of need, favoring products with a short halflife (6). The purpose of psychotherapy was to get the patient to verbalize his affect and emotions (1,2).

\section{Bibliographie:}

1- P.Clervoy- Le syndrome de Lazare, traumatisme psychique et destiné-Albin

Michel-2007

2- P. Clervoy\& coll. Les PSY en intervention- Doin 2009

3- L. Crocq Traumatisme psychique, prise en charge psychologique des victimes. Masson 2007.

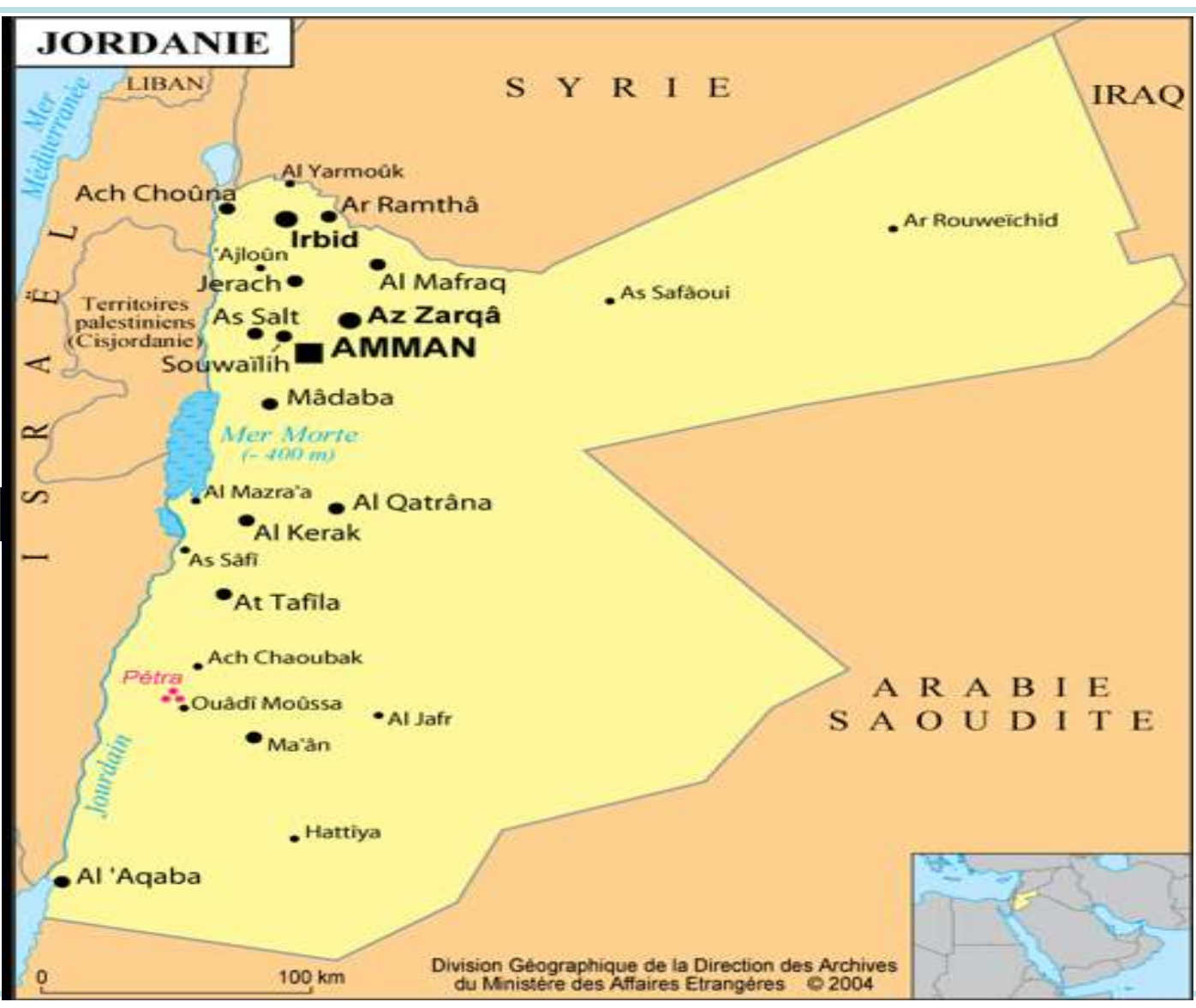

